\title{
Molecular characterization and expression patterns of the big defensin gene in freshwater mussel (Hyriopsis cumingii)
}

\author{
G.-L. Wang, X.-L. Xia, X.-L. Li, S.-J. Dong and J.-L. Li \\ Key Laboratory of Freshwater Germplasm Resources, \\ Ministry of Agriculture, Shanghai Ocean University, Shanghai, China \\ Corresponding author: J.-L. Li \\ E-mail: j1li2009@126.com
}

Genet. Mol. Res. 13 (1): 704-715 (2014)

Received March 11, 2013

Accepted October 20, 2013

Published January 29, 2014

DOI http://dx.doi.org/10.4238/2014.January.29.1

\begin{abstract}
Antimicrobial peptides (AMPs), of which big defensins are examples, are an important component of the natural defenses of most living organisms, and possess remarkable microbicidal activities. In the present study, using expressed-sequence tag sequences from a cDNA library and RACE, the full-length cDNA sequence of the big defensin gene from the triangle-shell pearl mussel, Hyriopsis cumingii, $(H c B D)$, was cloned. The gene consists of a 5'-untranslated region (UTR) of $166 \mathrm{bp}$, a 3'-UTR region of $96 \mathrm{bp}$, and an open reading frame of $342 \mathrm{bp}$ that encodes 113 amino acids, consisting of a 23 amino acid signal peptide and a mature peptide of 90 amino acids with a molecular mass of $12.5 \mathrm{kDa}$. Amino acid sequence analysis showed that the sequence contained a transmembrane domain and a hydrophobic region. The full-length amino acid sequence showed the highest similarity to an amphioxus (Branchiostoma floridae) sequence $(64 \%)$, and lower similarities to other known defensins $(\alpha-, \beta-$, and $\theta$-defensins, and insect defensins). Expression of $H c B D$ was relatively high in the mantle and blood, lower in other tested tissues, and absent in gill and foot tissues. Real-time quantitative PCR was used to investigate
\end{abstract}


$H c B D$ expression in various tissues at different time points after injection of Aeromonas hydrophila. At $4 \mathrm{~h}$ post-inoculation, $H c B D$ expression in the mantle, liver, intestine, gill, and foot was greater than in the control, with the greatest expression at $72 \mathrm{~h}$, while at $24 \mathrm{~h}$, expression in the liver, intestine, gill, and foot were at their lowest levels. These results suggest that $H c B D$ might play an important role in the host immune response. This study enriches the basic research on the big defensin family of antimicrobial peptides and lays foundations for further research on antimicrobial peptide expression and relevance to disease defense.

Key words: Hyriopsis cumingii; Big defensin; Induced expression; Immune response

\section{INTRODUCTION}

The triangle sail mussel, Hyriopsis cumingii Lea(Lamellibranchia, Unionoida, Unionidae), is a unique freshwater pearl mussel (Qiao et al., 2010). Aquaculture of mussels is a traditional industry that contributes enormously to the economic development of aquatic products. In recent years, however, the impact of various diseases is an increasingly serious problem (Wang et al., 2007; Xu et al., 2011). Increased resistance of bacteria towards antibiotic drugs has stimulated intensive efforts for the discovery and characterization of antimicrobial effectors. In natural conditions, the open circulatory system of a mussel makes it vulnerable to pathogen infection from the surroundings. The lack of acquired immunity means that a mussel's defense against invading microorganisms relies on the innate immune system that includes cellular and humoral immune components (Haug et al., 2004). Antimicrobial peptides (AMPs) are an important component of the natural defenses of most living organisms. These peptides are gene-encoded, relatively small $(<10 \mathrm{kDa})$, cationic, and amphipathic (Boman, 2003; Sang and Blecha, 2008). AMPs constitute the first line of innate immunity for mollusks exposed to various potential pathogens in the aquatic environment, and are considered "natural antibiotics" (Steiner et al., 1981; Sang and Blecha, 2008). The discovery of AMPs provides new clues for a fundamental understanding of the species-specific immune response, and for the establishment of further disease control practices in the aquaculture industry. AMPs have been isolated from a wide variety of animals (vertebrates and invertebrates) and plants, as well as bacteria and fungi (Reddy et al., 2004). These peptides exhibit broad-spectrum activity against a range of microorganisms, including gram-positive and gramnegative bacteria, protozoa, yeasts, fungi, and viruses. In mollusks, AMPs have been characterized mainly in seawater bivalves, such as the mussels Mytilus edulis and Mytilus galloprovincialis (Charlet et al., 1996; Mitta et al., 2000a). Using biochemical approaches and molecular cloning, four families of cysteine-rich AMPs have been identified in Mytilus spp.: the M. galloprovincialis defensins, myticins, mytilins, and mytimycin (Mitta et al., 2000b).

Big defensins are AMPs that possess remarkable microbicidal activities. The earliest well-characterized big defensin was from Tachypleus tridentatus. It consists of 79 amino acid residues, including a $\mathrm{C}$-terminal defensin domain and a highly hydrophobic $\mathrm{N}$-terminus (Saito et al., 1995). The former domain is more potent against gram-negative bacteria, while the latter displays greater activity against gram-positive bacteria. Zhao et al. cloned big defensin genes from Argopecten irradians (122 amino acid residues) and Venerupis philippinarum (94 
amino acid residues), and both were shown to inhibit the growth of gram-positive and gramnegative bacteria (Zhao et al., 2007; Zhao et al., 2010).

To the best of our knowledge, AMPs from freshwater shellfish have been reported only in $H$. cumingii (Xu and Faisal, 2010). The main objectives of this present study were to: i) clone the full-length cDNA of the big defensin from $\mathrm{H}$. cumingii $(\mathrm{HcBD})$; ii) examine the structural characteristics of the deduced amino acid sequence and; iii) investigate the tissue expression profiles of $H c B D$ before and after inoculation with a bacterial pathogen.

\section{MATERIAL AND METHODS}

\section{Animal treatment and RNA extraction}

Triangle sail mussels (3 years-old) were supplied by Weiwang Breeding New Technology Co. Ltd (Zhejiang Province, China). Healthy animals were reared in glass tanks (50 $\mathrm{cm}$ x $30 \mathrm{~cm}$ x $35 \mathrm{~cm}$; five individuals per tank) and supplied with sufficient oxygen. Mussels were fed daily with Chlorella for one week before experimentation.

For the bacterial challenge, $1 \mathrm{~mL}$ of activated Aeromonas hydrophila $\left(10^{8} \mathrm{cfu} /\right.$ $\mathrm{ml}$ ) was injected into the adductor muscles of 24 mussels. As controls, 24 mussels were similarly injected with $1 \mathrm{ml}$ of sterile LB broth to serve as controls (Cellura et al., 2007). Three mussels from each group were sampled at 2, 4, 6, 12, 24, 48, and $72 \mathrm{~h}$ post-injection. Mantle, blood, liver, intestine, gill, and foot tissues were collected from each mussel and used for the isolation of total RNA. RNA was extracted using RNAiso reagent according to the manufacturer protocol (TaKaRa, Japan), incubated with RNase-free gDNA Eraser (TaKaRa, Japan) and stored at $-80^{\circ} \mathrm{C}$.

\section{Cloning of the full-length cDNA of $\mathrm{HcBD}$}

Two specific primers, 3'GSP1 and 3'GSP2 (Table 1), were designed using Primer Premier v5.0. They were based on the sequence of the expressed-sequence tag (EST) in a cDNA library produced previously in our laboratory (Bai et al., 2009). The full-length cDNA of $H c B D$ was cloned by the rapid amplification of cDNA ends (RACE) method, using the 3'-Full Race Core Set v2.0 Kit (TaKaRa, Japan) according to the manufacturer protocol with 3' amplification nested-PCR. RACE reactions were firstly carried out in a $50 \mu \mathrm{L}$ outer PCR reaction volume containing $8 \mu \mathrm{L} 1 \mathrm{X}$ cDNA Dilution buffer, $2 \mu \mathrm{L} 10 \mathrm{mM}$ of gene-specific primer $1,2 \mu \mathrm{L} 10 \mathrm{mM}$ 3'-RACE outer primer, $4 \mu \mathrm{L}$ 10X LA PCR buffer $\left(\mathrm{Mg}^{2+}\right.$-free $), 3 \mu \mathrm{L} \mathrm{MgCl}_{2}(25 \mathrm{mM}), 0.25 \mu \mathrm{L}$ TaKaRa LA Taq $(5 \mathrm{U} / \mu \mathrm{L}), 2 \mu \mathrm{L}$ RACE-ready cDNA, and $28.75 \mu \mathrm{L} \mathrm{ddH}_{2} \mathrm{O}$. Reaction conditions were as follows: $94^{\circ} \mathrm{C}$ for $3 \mathrm{~min} ; 30$ cycles of $94^{\circ} \mathrm{C}$ for $30 \mathrm{~s}, 61^{\circ} \mathrm{C}$ for $30 \mathrm{~s}$ and $72^{\circ} \mathrm{C}$ for $60 \mathrm{~s} ; 72^{\circ} \mathrm{C}$ for $10 \mathrm{~min}$ and storage at $4^{\circ} \mathrm{C}$. Next, inner PCR reactions were carried out in a 50 $\mu \mathrm{L}$ reaction volume containing $1 \mu \mathrm{L}$ of the product from the previous step, $8 \mu \mathrm{L}$ dNTP mixture (2.5 mM), $5 \mu \mathrm{L}$ 10X LA PCR buffer $\alpha\left(\mathrm{Mg}^{2+}\right.$-free), $5 \mu \mathrm{L} \mathrm{MgCl}_{2}(25 \mathrm{mM}), 0.5 \mu \mathrm{L}$ TaKaRa LA Taq $(5 \mathrm{U} / \mu \mathrm{L}), 2 \mu \mathrm{L} 10 \mathrm{mM}$ gene-specific primer 2, $2 \mu \mathrm{L} 10 \mathrm{mM}$ 3'RACE inner primer, and 26.5 $\mu \mathrm{L}$ ddH2O. Reaction conditions were as follows: $94^{\circ} \mathrm{C}$ for $3 \mathrm{~min} ; 30$ cycles of $94^{\circ} \mathrm{C}$ for $30 \mathrm{~s}$, $63^{\circ} \mathrm{C}$ for $30 \mathrm{~s}$ and $72^{\circ} \mathrm{C}$ for $60 \mathrm{~s} ; 72^{\circ} \mathrm{C}$ for $10 \mathrm{~min}$. A fragment of $604 \mathrm{bp}$ was amplified using the $3^{\prime} \mathrm{RACE}$. The PCR product was ligated into the PMD19-T vector (TaKaRa, Japan), transformed into competent Escherichia coli DH5 $\alpha$ cells, plated on LB agar and incubated overnight at $37^{\circ} \mathrm{C}$. 
Positive clones containing an insert of the expected size were identified by colony PCR. Three of the positive clones were sequenced in both directions on an ABI PRISM 3730 Automated Sequencer using BigDye terminator v3.1 (Applied Biosystems, USA). The resulting sequences were verified and subjected to cluster analysis.

\begin{tabular}{lll}
\multicolumn{2}{c}{ Table 1. Primers used to study the big defensin gene of Hyriopsis cumingii. } \\
\hline Name & Sequence (5'-3') & PCR objective \\
\hline 3'-RACE outer primer & TACCGTCGTTCCACTAGTGATTT & 3'-RACE \\
3'-RACE inner primer & CGCGGATCCTCCACTAGTGATTTCACTATAGG & 3'-RACE \\
3'-GSP1 & CTCACACTACCTGCTGAATGCG & 3'-RACE \\
3'-GSP2 & CAGTATTCGTAGGGGCTGTAGT & 3'-RACE \\
BF-r & ACACTACCTGCTGAATGCG & RT-PCR \\
$\beta-$-AcF & GGCACAGGAATGGCTATCT & RT-PCR \\
$\beta-A c R$ & ACGGATAACACAAGGAAAGGAAAC \\
D3-F & ATGGATGGAAACACGGCTCT & quantitive PCR \\
D3-R & ATAATGGCAGCGATAGAAGAGATG & quantitive PCR \\
\hline
\end{tabular}

\section{Sequence analysis}

The identity of nucleotide and amino acid sequences was confirmed using the BLAST program (http://blast.ncbi.nlm.nih.gov/Blast.cgi). The open reading frame (ORF) of $H c B D$ cDNA was determined using ORF Finder (http://www.ncbi.nlm.nih.gov/projects/ gorf/). The putative amino acid sequence of the HcBD protein was analyzed for the presence of physical parameters, signal peptides, transmembrane structures, and hydrophobic regions using the Protparam program (Sigal P 3.0 server), TMHMM and ProtScale. A phylogenetic tree was constructed based on the deduced full-length amino acid sequence alignments using the neighbor-joining (NJ) algorithm and Maximum Likelihood method in the MEGA 4.1 program. The reliability of the estimated tree was evaluated using the bootstrap method with 1000 pseudo-replications. The protein's secondary structure was predicted using Jpred3 (http://www.compbio.dundee.ac.uk/www-jpred/index.html), and tertiary structure was analyzed using ESyPred3D Web Server 1.0 (http://www.fundp.ac.be/sciences/biologie/urbm/ bioinfo/esypred/) (Lambert et al., 2002).

\section{Semi-quantitative analysis of $H c B D$ expression}

Mantle, blood, liver, kidney, stomach, intestine, gill, and foot tissues (100 mg of each) were collected from healthy mussels. Total RNA was extracted as above. A volume of $2 \mu \mathrm{L}$ RNA was used for cDNA reverse transcription. $\beta$-actin served as control. The primers used (BF-f, BF-r, $\beta$-AcF, $\beta-A c R$ ) are listed in Table 1, and the PCR conditions were as follows: $94^{\circ} \mathrm{C}$ for $3 \mathrm{~min}$; then cycles of $94^{\circ} \mathrm{C}$ for $30 \mathrm{~s}$, annealing temperature for $30 \mathrm{~s}, 72^{\circ} \mathrm{C}$ for $60 \mathrm{~s}$; followed by $72^{\circ} \mathrm{C}$ for $10 \mathrm{~min}$ and storage at $4^{\circ} \mathrm{C}$. The optimum number of cycles for amplifying $H c B D$ and $\beta$-actin were 36 and 31, respectively, and the optimum annealing temperatures were $55^{\circ} \mathrm{C}$ and $60^{\circ} \mathrm{C}$, respectively. During the optimum annealing cycles, $H c B D$ and $\beta$-actin were both in their exponential growth period, and the amplified product sizes were 365 and $145 \mathrm{bp}$, respectively. The expression of $H c B D$ in eight tissues was detected by $1.5 \%$ agarose gel electrophoresis. 


\section{Real-time PCR analysis of $H c B D$ expression}

The expression of the $H c B D$ transcript in six different tissues at six time points after bacterial challenge was measured by quantitative real-time (RT)-PCR using a CFX96 real-time system. Approximately $1 \mu \mathrm{g}$ RNA from each sample was reverse-transcribed using the PrimeScript RT Reagent Kit with a gDNA Eraser (TaKaRa, Japan). The first-strand cDNA was subsequently used as the template for PCR with the D3-F and D3-R primers, while $\beta$-actin was amplified using the $\beta$-AcF and $\beta$-AcR primers. The latter gene served as the internal control for cDNA normalization. The quantitative RT-PCR mixture consisted of $1 \mu \mathrm{L}$ cDNA sample, $8.2 \mu \mathrm{L}$ ddH $_{2} \mathrm{O}, 10 \mu \mathrm{L} 2 \mathrm{X}$ SYBR Premix Ex taq ${ }^{\mathrm{TM}}$ (TaKaRa, Japan) and $0.8 \mu \mathrm{L} 10 \mu \mathrm{M}$ of each gene-specific primer. The PCR cycling condition were: $95^{\circ} \mathrm{C}$ for $30 \mathrm{~s} ; 45$ cycles of $95^{\circ} \mathrm{C}$ for $5 \mathrm{~s}$ and $60^{\circ} \mathrm{C}$ for $30 \mathrm{~s}$. This was followed by dissociation curve analysis at $95^{\circ} \mathrm{C}$ for $15 \mathrm{~s}, 60^{\circ} \mathrm{C}$ for $60 \mathrm{~s}$ and $95^{\circ} \mathrm{C}$ for $15 \mathrm{~s}$ to verify the amplification of a single product. The threshold cycle (CT) values were determined by the CFX96 software. Data were exported into a Microsoft Excel spreadsheet for subsequent analysis, where the relative expression ratios of the target gene in treated groups versus control were calculated using a $2^{\triangle \triangle \mathrm{CT}}$ method. One-way ANOVA tests were performed using SPSS 19.0 to determine whether there were any significant differences between the tested groups and the control groups at different time points in the same tissue.

\section{Statistical analysis}

Data from the qRT-PCR is presented as the means \pm SE. Differences between the tested groups and the control groups were analyzed by a one-way ANOVA with post-hoc Dunnett's T3 test. Significance was accepted at the level of $\mathrm{P}<0.05$.

\section{RESULTS}

\section{cDNA cloning and sequencing of the $H c B D$ gene}

The total RNA of the mantle from $H$. cumingii separated into three clear bands after $1.5 \%$ agarose gel electrophoresis. This agrees with the characteristics reported previously for total RNA from $H$. cumingii (Li et al., 2010). A full-length cDNA of 604bp encoding $H c B D$ was obtained after 3'RACE. The full-length cDNA sequence of $H c B D$ was deposited in GenBank with the accession No. HQ400674. HcBD was 604 bp long, consisting of a 5'-untranslated region (UTR) of $166 \mathrm{bp}$, a $342 \mathrm{bp} \mathrm{ORF}$ encoding 113 amino acid residues (Figure 1), and a 3'-UTR of 96 bp that included a poly-A signal sequence. The polyadenylation signal (AATAA) was found 2 bp upstream of the poly-A tail.

\section{Amino acid sequence analysis of $\mathrm{HcBD}$}

The molecular formula for the 113 amino acids deduced from the HcBD cDNA is $\mathrm{C}_{564} \mathrm{H}_{876} \mathrm{~N}_{152} \mathrm{O}_{153} \mathrm{~S}_{10}$. This is a protein of $12.6 \mathrm{kDa}$ with a theoretical isoelectric point of 8.51 and an instability index of 41.62, which classifies it as unstable. Multiple alignments of the $H c B D$ sequence with big defensin genes from T. tridentatus (P80957), B. floridae (ADH03419), A. ir- 
radians (ABC61319) and Branchiostoma belcheri tsingtauense (AAO18674) showed that there are six cysteine sites conserved within each of the sequences (Figure 2).

\begin{tabular}{|c|c|}
\hline TCGAAT TCCTCAGT T'TCT GAGAAGGACTGAAAAA TACT CACACTACD & \\
\hline GGATTT'TCAACACTGTATTCCGACTAACCATCT TAATTTCATCTTTCTCTGGCAAAGAC & 120 \\
\hline CTCGGTGCAGCA TTTCAATTTTCGGATTCTTGAAAAAA TCAACCATGAACCAAAAGAA & 180 \\
\hline I $\quad \begin{array}{lllllllll}\mathbf{H} & \mathbf{Q} & \mathbf{K} & \mathbf{H}\end{array}$ & \\
\hline GGTCTTTGCCTGCTTTTCCTGGTACTGCTGTTGTCGCCACACAATATAATGGCAGCGAT & 240 \\
\hline 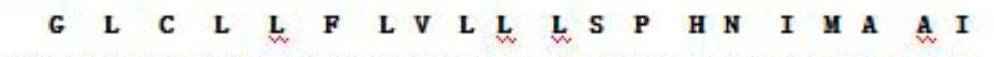 & \\
\hline AGAAGAGATGGAAGTGCGACACACGCGACAGGTGGCGATACCACCAGTATTCGTAGGGGC & 300 \\
\hline 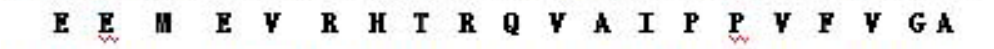 & \\
\hline TGTAGTTAGTCC TTAT GTATTTCTAGCTCTTCTAGCCATA TACGGTGCTGCTGTCCTGAT & 360 \\
\hline 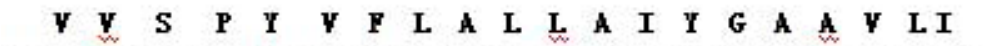 & \\
\hline TAGTAATGGAGTTCAAAAAGCATCTTCAGATAGCCATTCCTGTGCCAACAATCGTGCATG & 420 \\
\hline $\begin{array}{llllllllllllllllllll}\mathbf{S} & \mathbf{H} & \mathbf{G} & \mathbf{Y} & \mathbf{Q} & \mathbf{K} & \mathbf{A} & \mathbf{S} & \mathbf{S} & \mathbf{D} & \mathbf{S} & \mathbf{H} & \mathbf{S} & \mathbf{C} & \mathbf{A} & \mathbf{H} & \mathrm{I} & \mathbf{R} & \mathbf{G} & \boldsymbol{W}\end{array}$ & \\
\hline GTGTCGTCTATCTTGCTTCAGTCATGAATACGTGGACTGGTACAATACA GCTGTGTGCGG & 480 \\
\hline $\begin{array}{llllllllllllllllllll}\mathbf{C} & \mathbf{R} & \mathbf{L} & \mathbf{S} & \mathbf{C} & \mathbf{F} & \mathbf{S} & \mathbf{H} & \mathbf{E} & \mathbf{Y} & \mathbf{Y} & \mathbf{D} & \mathbf{W} & \mathbf{Y} & \mathbf{H} & \mathbf{T} & \mathbf{A} & \mathbf{Y} & \mathbf{C} & \mathbf{G}\end{array}$ & \\
\hline СTATTACAAATGCTGCCGGCCAAAA TAGATGACCAAATAACCTTGAATTATATTTATCAT & 540 \\
\hline 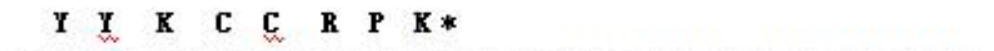 & \\
\hline GTAATTTCATTTCGATTAATTAAAATGTTCAATAATCAAAAAAAAAAAAAAAAAAAAAAAA & 60 \\
\hline AAA & \\
\hline
\end{tabular}

Figure 1. $H c B D$ cDNA sequence and the predicted amino acid sequence. Nucleotide residues are numbered on the right. ATG in the open box indicates the start codon, and asterisk indicates the stop codon. The polyadenylation signal "AATAA" is underlined.

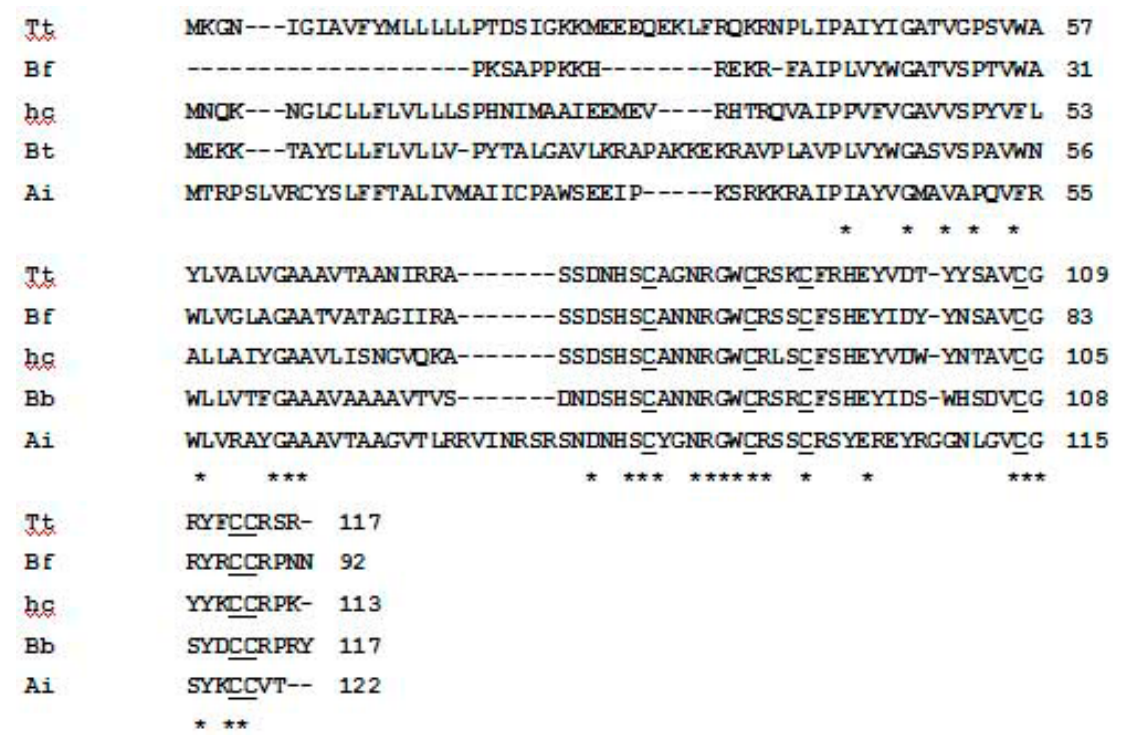

Figure2. Multiple alignment of $\mathrm{HcBD}$ and other known big defensin sequences. Asterisks indicate the residues that are highly conserved in all big defensins. "C" indicates the conserved position of the cysteine residues. 
The amino acid sequence of HcBD was analyzed by NN and HMM models on the SigalP 3.0 server, and the results indicate that a signal peptide of 23 amino acids is present at the at $\mathrm{N}$-terminus before the mature peptide. HcBD was predicted by TMHMM to contain transmembrane structures in the regions between residues 7 and 26, and residues 41 and 63. The six conserved cysteine sites are each located outside these transmembrane regions. ProtScale analysis showed that HcBD contains hydrophobic regions that are strong in the regions between residues 10 and 30, and residues 40 and 70 , but relatively weak in the regions between residues 85 and 95, and residues 100 and 110 .

\section{Phylogenetic analysis of defensin genes}

The deduced amino acid sequence of HcBD shows $64 \%$ identity with the big defensin from B. floridae (GenBank accession no. ADH03419), and 47 and $45 \%$ identity with big defensins from B. belcheri tsingtauens (GenBank accession no. AAO18674) and T. tridentatus (GenBank accession No. P80957), respectively. Multiple alignments of HcBD with other known big defensins (from T. tridentatus, B. floridae, A. irradians and B. belcheri tsingtauense) reveal that a consensus conserved pattern of C-X6-C-X3-C-X13(14)-C-X4-C-C in the mature peptides of these big defensins. Sequence identity and the common conserved sequence characteristics indicate that HcBD belongs to the big defensin family of AMPs.

The phylogenetic tree constructed using the NJ method for amino acid sequences indicates that different types of defensins and defensins from different species are distributed independently in distinct branches (Figure 3). Defensins from the mussels M. edulis, M. galloprovincialis and the oyster Crassostrea gigas with defensins from arthropods belong to the insect defensins, $\alpha$-, $\beta$-, and $\theta$-defensins cluster together, while HcBD clusters with other known big defensins. This reveals that the big defensins is a group different from traditional defensins.

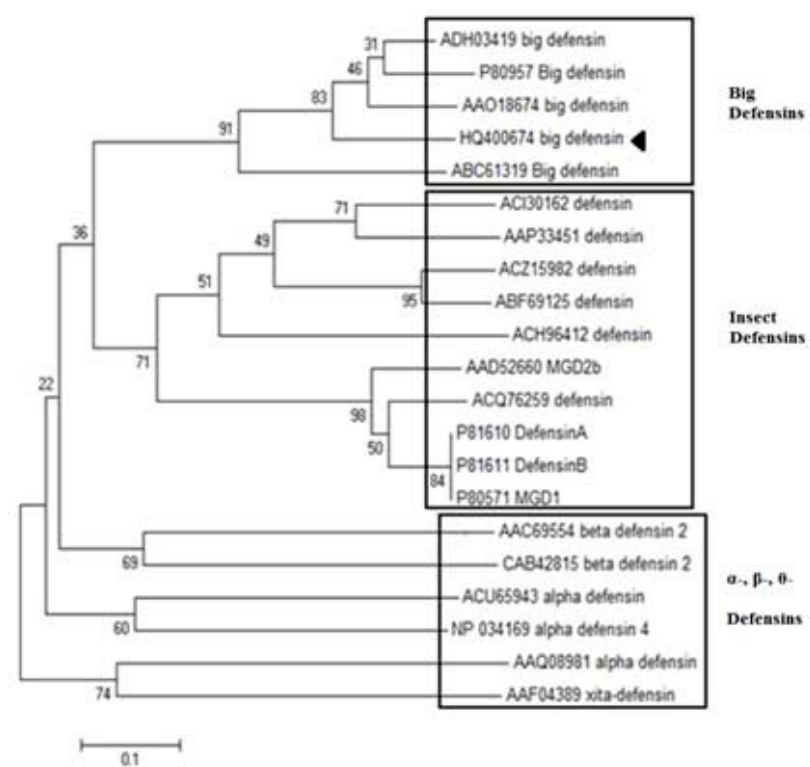

Figure 3. Unrooted phylogenetic tree of defensins from various animals. $H c B D$ is marked with a solid triangle ( 


\section{Constitutive expression of $\mathrm{HcBD}$ in different tissues}

Expression of $H c B D$ in different tissues was analyzed using RT-PCR. As shown in Figure 4, $H c B D$ mRNA was detected in the mantle, blood, liver, kidney, stomach and intestinal tissues. $H c B D$ expression was higher in the mantle and blood and lower in liver, kidney, stomach and intestine. No expression of $H c B D$ was detected in gill and foot tissues.

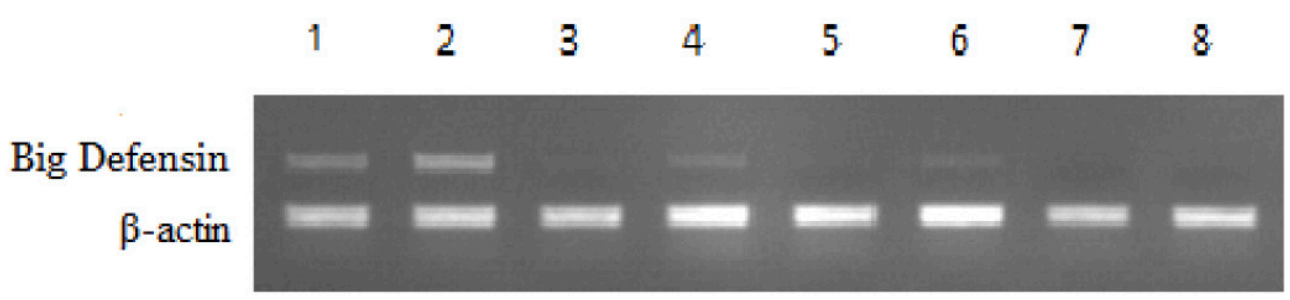

Figure 4. Tissue distribution of the $H c B D$ transcript by RT-PCR. Lane $1=$ mantle; lane $2=$ blood; lane $3=$ liver; lane $4=$ kidney; lane $5=$ stomach; lane $6=$ intestine; lane $7=$ gill; lane $8=$ foot.

\section{Quantification of $H c B D$ mRNA expression after a challenge with A. hydrophila}

Real-time RT-PCR was employed to quantify $H c B D$ expression kinetics after bacterial challenge. During the experiment, expression of $\beta$-actin was little changed after bacterial challenge in each of the tissues under examination, which excluded the possibility that any differences in $H c B D$ expression were caused by variations in the input RNA, efficiency of cDNA synthesis, or any other PCR artifact. A dissociation curve showed a single peak at the melting temperature expected for the amplicons under investigation, suggesting the amplifications were gene-specific. The standard curve showed a linear relationship, meaning it could be used for accurate quantification over a wide range of values. No fluorescence was detected in the negative control reactions, which verified that the reaction system was free from contamination.

Temporal expression of $H c B D$ after bacterial challenge is shown in Figure 5. In the mantle, $H c B D$ expression was greatest at $4 \mathrm{~h}$, lowest at $12 \mathrm{~h}$, upregulated gradually at $24 \mathrm{~h}$, and was moderately high after $48 \mathrm{~h}$. In the blood, $H c B D$ expression was lowest at $6 \mathrm{~h}$ and peaked at $72 \mathrm{~h}$. In the liver, except at $6 \mathrm{~h}$ and $24 \mathrm{~h}, H c B D$ expression was greater than that seen in the control group: after peaking at $4 \mathrm{~h}$, expression decreased to its lowest level at $24 \mathrm{~h}$, before upregulation at $48 \mathrm{~h}$, with expression remaining stable thereafter. In the intestine, expression peaked at $4 \mathrm{~h}$, was lowest at $24 \mathrm{~h}$, upregulated at 48 $\mathrm{h}$ and then remained stable. In the gill, expression was greater than the control group at 2,4 , and $12 \mathrm{~h}$, it peaked at $4 \mathrm{~h}$, was lowest at $24 \mathrm{~h}$, upregulated at $48 \mathrm{~h}$ and was thereafter stable. Finally, the expression kinetics of $H c B D$ in the foot tissue were similar to the gill tissue. Overall, after bacterial challenge, expression of $H c B D$ in the liver, intestine, gill and foot tissues was greatest at $4 \mathrm{~h}$ and lowest at $24 \mathrm{~h}$, distinguishing it from the expression pattern in the blood. 

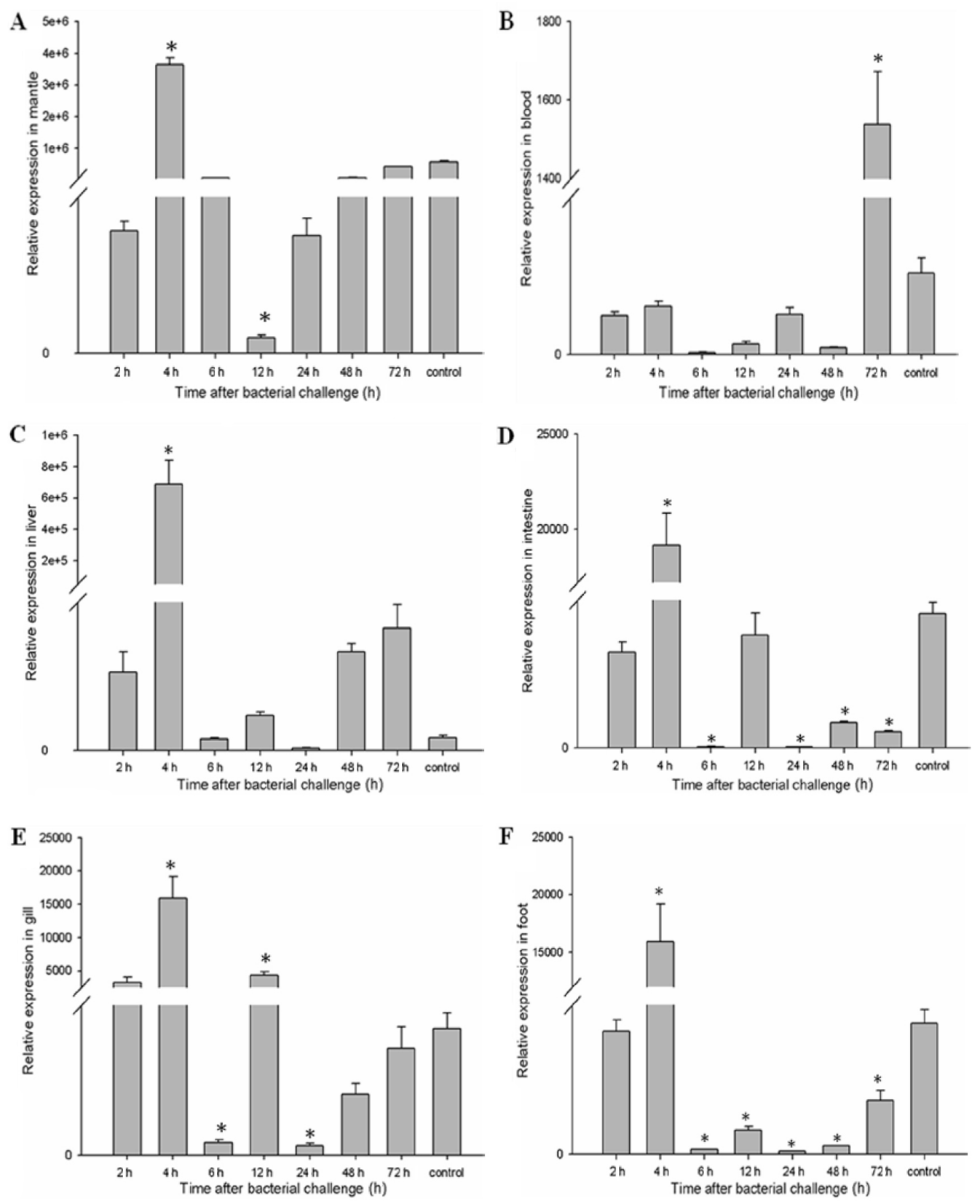

Figure 5. Quantitative expression profile of $H c B D$ in various tissues after bacterial challenge. The relative expression was calculated based on the standard curve and normalized to the $\beta$-actin mRNA level in six tissues at 2, 4, 6, 12, 24, 48, and $72 \mathrm{~h}$. Data from qRT-PCR are presented as mean \pm SE. ${ }^{*} \mathrm{P}<0.05$. A. Mantle; B. blood; C. liver; D. intestine; E. gill; F. foot. 


\section{DISCUSSION}

The full-length cDNA of $H c B D$ consists of $604 \mathrm{bp}$ with an ORF of $342 \mathrm{bp}$ encoding 113 amino acids. The propeptide contains a signal peptide of 23 amino acids and a mature peptide of 90 amino acids. The amino acid sequence indicates that the sequence contains distinct transmembrane structures and hydrophobic regions. The sequence contains features common to other AMPs: $\alpha$-helices, overall positive charge, and strong hydrophobic regions. Sequence alignment with other known big defensins showed the presence of six conserved cysteine residues forming the consensus pattern: C-X6-C-X3-C-X13(14)-C-X4-C-C. Thus, the disulfide array in HcBD is postulated to be identical to that seen in the big defensins in horseshoe crab and bay scallop (Cysl-Cys5, Cys2-Cys4, Cys3-Cys6). Furthermore, the disulfide array in HcBD is similar to that of $\beta$-defensin in bovine neutrophils (Yount et al., 1999), but different from the classical CS $\alpha \beta$ motif found in invertebrate defensins (Cys1-Cys4, Cys2- Cys5, Cys3-Cys6). In the four known kinds of animal defensins ( $\alpha-, \beta-, \theta$ - and insect defensins), disulfide connection type is an important basis for classification (Gueguen et al., 2006; Yenugu et al., 2006; Derache et al., 2009; Dezoysa et al., 2010). The disulfide connection types in these four kinds of defensins are respectively: Cysl-Cys6, Cys2-Cys4, Cys3-Cys5; Cysl-Cys5, Cys2-Cys4, Cys3-Cys6; Cysl-Cys6, Cys2-Cys5, Cys3-Cys4; and Cysl-Cys4, Cys2-Cys5, Cys3-Cys6. The disulfide connection type in HcBD (C-X6-C-X3-C-X13(14)-C- X4-C-C) is different from the above four types, but identical to other known big defensins. In addition, the arrangement of the cysteines, their neighboring amino acids, the spacing between the cysteines, and the greatest identity (64\%) with the big defensin from $B$. floridae, further indicate that $\mathrm{HcBD}$ is a new member of the big defensin family.

Northern blotting analysis demonstrated that the big defensin from $A$. irradians was predominantly expressed in hemocytes, but it was also detected in the hemocyte-rich gills of the scallop, while there seemed to be no mRNA expression in the mantle, hepatopancreas, gonad, or adductor muscle. In this study, $H c B D$ was found to be expressed in the mantle, blood, liver, kidney, stomach and intestine, with greatest expression in mantle and blood; there was no expression in gill and foot tissues. This result is inconsistent with the data of other research (Zhao et al., 2007; Costa et al., 2009), and the differences could be due to the use of fresh vs seawater conditions, and different RNA detection methods. Moreover, northern blotting is much more sensitive than RT-PCR. The open circulatory system means that the immune system in shellfish is different from higher animals, and the mantle is the first line of immune defense. Immune factors, such as lysosome, agglutinin, and AMPs, play important roles in host defenses (Cheng, 1981), and therefore, high expression of $H c B D$ in the mantle and blood would be expected.

Induced expression of big defensin after bacterial challenge has been reported only in marine mussels, and only in the hemocytes (Zhao et al., 2007; Zhao et al., 2010). The present study indicates that HcBD likely participates in immune processes, given the significant increases in expression observed in several tissues after injection of $A$. hydrophila. As shown in Figure 5, $4 \mathrm{~h}$ after infection, transcript levels of $H c B D$ were greatest in the mantle, liver, intestine, gill and foot, and, apart from the mantle, lowest expression in these tissues was at $24 \mathrm{~h}$, with significant upregulation at $48 \mathrm{~h}$ before expression stabilized. $H c B D$ expression prior to $4 \mathrm{~h}$ was probably high due to a stress response, and then expression levels increased significantly. $H c B D$ expression decreased from $6 \mathrm{~h}$ to a minimum at $24 \mathrm{~h}$ due to tissue infection, while after $48 \mathrm{~h}$, immune regulation in various tissues caused upregulation of expression. A number of hypotheses concerning the decrease in $H c B D$ expression can be considered, including: i) recruitment of peptide-producing cells towards the site of 
injection; ii) apoptosis affecting the relevant cell types or; iii) activation of cells expressing HcBD leading to a release of the peptide and a decrease in gene transcription (Mitta et al., 2000a).

The mantle of $H$. cumingii is not only the first line of innate immunity, as it also has vessels containing hemocytes conferring double defensive abilities. Thus, after bacterial injection, the immune response is different from that in other tissues. The big defensin in horseshoe crab has been cloned and isolated (Saito et al., 1995; Kawabata et al., 1997) and was found to be located in large and small granules in the hemocytes. In the present study, expression of $H c B D$ was upregulated at $4 \mathrm{~h}$, and $24 \mathrm{~h}$, lowest at $6 \mathrm{~h}$, but reached a peak at $72 \mathrm{~h}$. Similar kinetics (a decrease followed by a significant increase) have been observed in the hemocytes of Penaeus vannamei and Carcinus maenas after microbial challenge (Smith and Ratcliffe, 1980; Munoz et al., 2002). During the first phase (corresponding to the first $12 \mathrm{~h}$ post-challenge), hemocytes constitutively produced AMP mRNA and protein. The decrease of AMPs was the result of a decrease in AMP-expressing hemocytes: these cells leave the blood circulation and most other body tissues to migrate towards the site of the injured tissues. Consequently, expression of $H c B D$ in blood is decreased during the first phase. During the second phase (at about 48$72 \mathrm{~h}$ post-challenge), the AMP transcriptional activity in the blood gradually increases, thus we assume that the AMP upregulation in hemocytes reflects an induced proliferation process. At $72 \mathrm{~h}$ post-stimulation, transcriptionally active, young or maturating hemocytes (but that are comparatively AMP-poor) are probably produced intensively and released early from hematopoietic tissues. Because of this proliferative process, there is a concomitant and dramatic increase in AMP expression in the blood. Indeed, the greatest expression of $H c B D$ in blood in the present experiment is consistent with these earlier findings.

In conclusion, this is the first report on the big defensin gene in H. cumingii. Gene expression was detected in many tissues except gill and foot, and was highest in the mantle and blood. After bacterial challenge, with the exception of the blood, expression of the gene was greatest at $4 \mathrm{~h}$ and lowest at $24 \mathrm{~h}$ in the liver, intestine, gill and foot tissues. The results not only enrich the basic research on the AMP gene family in $\mathrm{H}$. cumingii and freshwater mussels, providing improved understanding of the immune system and how it may be manipulated to enhance immunity in freshwater shellfish, but also lay a theoretical foundation for further practical application in studies of immune defenses.

\section{ACKNOWLEDGMENTS}

Research supported by the National Natural Science Foundation of China (\#31101939), the Key Fundamental Research Project of Shanghai Municipal Science and Technology Committee (\#10JC1406300) and the Innovation Program of Shanghai Municipal Education Commission (\#13ZZ128).

\section{REFERENCES}

Bai Z, Yin Y, Hu S, Wang G, et al. (2009). Identification of genes involved in immune response, microsatellite, and SNP markers from expressed sequence tags generated from hemocytes of freshwater pearl mussel (Hyriopsis cumingii). Mar. Biotechnol. 11: 520-530.

Boman HG (2003). Antibacterial peptides: basic facts and emerging concepts. J. Intern. Med. 254: 197-215.

Cellura C, Toubiana M, Parrinello N and Roch P (2007). Specific expression of antimicrobial peptide and HSP70 genes in response to heat-shock and several bacterial challenges in mussels. Fish Shellfish Immunol. 22: 340-350.

Charlet M, Chernysh S, Philippe H, Hetru C, et al. (1996). Innate immunity. Isolation of several cysteine-rich antimicrobial 
peptides from the blood of a mollusc, Mytilus edulis. J. Biol. Chem. 271: 21808-21813.

Cheng T (1981). Bivalves Invertebrate Blood Cells. Academic Press, New York. 233-330.

Costa MM, Prado-Alvarez M, Gestal C, Li H, et al. (2009). Functional and molecular immune response of mediterranean mussel (Mytilus galloprovincialis) haemocytes against pathogen-associated molecular patterns and bacteria. Fish Shellfish Immun. 26: 515-523.

Derache C, Labas V, Aucagne V, Meudal H, et al. (2009). Primary structure and antibacterial activity of chicken bone marrow-derived beta-defensins. Antimicrob. Agents Chemother. 53: 4647-4655.

Dezoysa M, Nikapitiya C, Oh C, Whang I, et al. (2010). Molecular evidence for the existence of lipopolysaccharideinduced TNF- $\alpha$ factor (LITAF) and Rel/NF-kB pathways in disk abalone (Haliotis discus discus). Fish Shellfish Immun. 28: 754-763.

Gueguen Y, Herpin A, Aumelas A, Garnier J, et al. (2006). Characterization of a defensin from the oyster Crassostrea gigas. Recombinant production, folding, solution structure, antimicrobial activities, and gene expression. J. Biol. Chem. 281: 313-323.

Haug T, Stensvag K, Olsen MO, Sandsdalen E, et al. (2004). Antibacterial activities in various tissues of the horse mussel, Modiolus modiolus. J. Invertebr. Pathol. 85: 112-119.

Kawabata S, Saito T, Saeki K, Okino N, et al. (1997). cDNA cloning, tissue distribution, and subcellular localization of horseshoe crab big defensin. Biol. Chem. 378: 289-292.

Lambert C, Léonard N, De Bolle X and Depiereux E (2002). ESyPred3D: Prediction of proteins 3D structures. Bioinformatics 18: 1250-1256.

Li XL, Wang GL, Li JL and Yuan YM (2010). Full-length cDNA cloning and encoding protein structure analysis of GPX in Hyriopsis cumingii. Hereditas 32(4):360-368.

Mitta G, Hubert F, Dyrynda EA, Boudry P, et al. (2000a). Mytilin B and MGD2, two antimicrobial peptides of marine mussels: gene structure and expression analysis. Dev. Comp. Immunol. 24: 381-393.

Mitta G, Vandenbulcke F and Roch P (2000b). Original involvement of antimicrobial peptides in mussel innate immunity. FEBS Lett. 486: 185-190.

Muñoz M, Vandenbulcke F, Gueguen Y and Bachère E (2003). Expression of penaeidin antimicrobial peptides in early larval stages of the shrimp Penaeus vannamei. Dev. Comp. Immunol. 27:283-289.

Qiao D, Liu J, Ke C, Sun Y, et al. (2010). Structural characterization of polysaccharides from Hyriopsis cumingii. Carbohyd. Polym. 82: 1184-1190.

Reddy KV, Yedery RD and Aranha C (2004). Antimicrobial peptides: premises and promises. Int. J. Antimicrob. Agents 24: 536-547.

Saito T, Kawabata S, Shigenaga T, Takayenoki Y, et al. (1995). A novel big defensin identified in horseshoe crab hemocytes: isolation, amino acid sequence, and antibacterial activity. J. Biochem. 117: 1131-1137.

Sang Y and Blecha F (2008). Antimicrobial peptides and bacteriocins: alternatives to traditional antibiotics. Anim. Health Res. Rev. 9: 227-235.

Smith VJ and Ratcliffe NA (1980). Cellular defense reactions of the shore crab, Carcinus maenas: In vivo hemocytic and histopathological responses to injected bacteria. J. Invertebr. Pathol. 35: 65-74.

Steiner H, Hultmark D, Engström A, Bennich H, et al. (1981). Sequence and specificity of two antibacterial proteins involved in insect immunity. Nature 292: 246-248.

Wang G, Yuan Y and Li J (2007). SSR analysis of genetic diversity and phylogenetic relationships among different populations of Hyriopsis cumingii from the five lakes of china. Fish. China 31: 152-158.

Xu Q, Guo L, Xie J and Zhao C (2011). Relationship between quanlity of pearl cultured in the triangle mussel Hyriopsis cumingii of different ages and its immune mechanism. Aquaculture 315: 196-200.

Xu W and Faisal M (2010). Defensin of the zebra mussel (Dreissena polymorpha): molecular structure, in vitro expression, antimicrobial activity, and potential functions. Mol. Immunol. 47: 2138-2147.

Yenugu S, Chintalgattu V, Wingard CJ, Radhakrishnan Y, et al. (2006). Identification, cloning and functional characterization of novel beta-defensins in the rat (Rattus norvegicus). Reprod. Biol. Endocrinol. 4: 7.

Yount NY, Yuan J, Tarver A, Castro T, et al. (1999). Cloning and expression of bovine neutrophil beta-defensins. Biosynthetic profile during neutrophilic maturation and localization of mature peptide to novel cytoplasmic dense granules. J. Biol. Chem. 274: 26249-26258.

Zhao J, Song L, Li C, Ni D, et al. (2007). Molecular cloning, expression of a big defensin gene from bay scallop Argopecten irradians and the antimicrobial activity of its recombinant protein. Mol. Immunol. 44: 360-368.

Zhao J, Li C, Chen A, Li L, et al. (2010). Molecular characterization of a novel big defensin from clam Venerupis philippinarum. PLoS One 5: e13480. 